\title{
Incidence of Diarrhea in Children Living in Urban Slums in Salvador, Brazil
}

\author{
Maria Clotildes N. de Melo ${ }^{1}$, José A.A.C. Taddei ${ }^{2}$, Daniel R. Diniz-Santos ${ }^{1}$, Camilo Vieira ${ }^{1}$, \\ Nadya B. Carneiro ${ }^{1}$, Rita Franca Melo ${ }^{1}$ and Luciana R. Silva ${ }^{1}$ \\ ${ }^{1}$ Division of Pediatric Gastroenterology and Hepatology, Professor Hosannah Oliveira Pediatric Centre, Federal University of Bahia; Salvador, \\ $B A ;{ }^{2}$ Department of Nutrition, Medical School of São Paulo, Federal University of São Paulo; São Paulo, SP, Brazil
}

\begin{abstract}
Diarrhea remains a major health issue in developing countries, with high morbidity and mortality rates. Determining the incidence of acute diarrhea in children and its associated factors is crucial to the planning of preventive approaches. The objective of this study was to determine the incidence of diarrhea and to assess some relevant associated factors to it in children younger than $\mathbf{4 0}$ months living in two slums of Salvador, Brazil. This is the first prospective cohort, community-based study that was performed in two periurban slums of Salvador, Brazil. Eightyfour children younger than $\mathbf{4 0}$ months were randomly selected and visited every other day for one year. The chisquare test was used to evaluate the occurrence of diarrhea and its associated factors. During the surveillance period, 232 diarrhea episodes were identified, resulting in an incidence rate of 2.8 episodes/child/year. In average (mean value of 84 children),each child suffered 11.1 days of diarrhea per year, yielding an average duration of 3.9 days per episode. The highest incidence rates were found among children under one year old. Early weaning, male sex, malnutrition, having a mother younger than 25 years or who considered her child malnourished, missed immunizations and previous pneumonia were associated factors for suffering diarrheal episodes. The rates of incidence and duration of diarrhea that we found are in accordance to those reported by others. Additionally, our results reinforce the importance of environmental and health-related associated factors to the onset of diarrhea. Key-Words: Diarrhea, children, sewerage.
\end{abstract}

Acute diarrhea remains as one of the most prevalent diseases affecting young children in developing countries in spite of the growing knowledge achieved in recent years. Even though programs sponsored by World Health Organization (WHO) and other improvements on the quality of life of several populations have succeeded in decreasing mortality rates, the incidence of diarrhea in children younger than five years in developing countries remains high, at 3.2 cases per child per year [1-3], but rates can be as high as 11 episodes of diarrhea per child per year in extremely poor areas [4]. At the end of $20^{\text {th }}$ century, 2.5 million deaths are estimated to have occurred worldwide each year, making diarrhea responsible for $21 \%$ of deaths of children younger than five years old [3].

Estimates of the burden of diarrhea in developing countries are scarce, and may considerably underestimate the magnitude of the disease because of methodological issues both on studies reporting such rates and on systems used to gather epidemiological data [3,5-7]. Several studies present diverse rates of incidence, duration and prevalence of diarrhea, probably because of divergent methods and intrinsic disparities among the populations studied [7-12].

Acute diarrhea might strike individuals at any age, but it is mostly an infant's disease, affecting especially those younger than one year $[4,13,14]$. The period of weaning is a major factor to favor the occurrence of diarrhea, while many other risk factors should also be considered, such as low socioeconomic level, poor hygiene habits, unsavory dwelling, elevated Received on 9 September 2007; revised 9 January 2008.

Address for correspondence: Dr. Camilo Vieira. Rua do Timbó, 623, Ed. Iguatemi Sul, Apto 802, Caminho das Árvores, Zip code: 40820-660. Salvador, BA, Brazil. E-mail: dinizsantosdr@terra.com.br.

The Brazilian Journal of Infectious Diseases

2008;12(1):89-93. (C) 2008 by The Brazilian Journal of Infectious Diseases and Contexto Publishing. All rights reserved. environmental exposure to enteropathogens and poor nutritional status $[4,15-20]$.

The objective of this study was to determine the incidence of diarrhea in children who live in poor conditions and to describe possible associations between the incidence and the duration of the episodes of diarrhea and age, sex, nutritional status, duration of breastfeeding period, previous diseases, vaccination and socioeconomic and demographic status.

\section{Material and Methods}

This is a prospective study that was performed in Nova Divinéia and Vila Balbino, two urban slums in Salvador, Brazil, whose demographic, social and sanitary conditions are described elsewhere [20]. Data about epidemiology of diarrhea or its seasonal characteristics in these two slums are unknown. The slums were selected according to their sanitary structure (described in detail in reference 20): Nova Divinéia (hereafter termed community 1) had no sanitary improvement, while Vila Balbino (hereafter termed community 2) had a drainage and sewerage system that drained rain water and detritus.

Eighty-four children younger than 40 months ( 42 from each slum) were enrolled in the study after being selected at random among those who lived in the slums and were visited every other day for one year by members of the research team who inquired their caregivers about the occurrence of diarrhea on the day of the visitation or on the previous day. This sample size allows the identification of $\mathrm{X} \%$ differences on the incidence of diarrhea between the two studied communities with alfa of .05 and a beta of .20 . Informed consent was obtained from the parents or legal guardians of all children and the whole research was conducted according to the guidelines for research involving humans of the Ethics Committee of the Professor Edgard Santos University Hospital, Federal University of Bahia, Brazil. 
Diarrhea was defined by the passing of three or more loose stools on a 24-hour period regardless of the presence of blood, mucus or pus, as detected by the parents or by the responsible caregiver. An episode of diarrhea was considered to be the occurrence of diarrhea after three or more days free of diarrhea.

Data about demographic characteristics of children and their family was collected at the beginning of the study. A follow up questionnaire developed and applied by authors was administered in domiciliary visitation every other day, and the duration and clinical outcome of the episodes of diarrhea were registered. A responsible adult trained was available in all domiciliary visitations.

The independent variables studied were related to children (sex, age, duration of breastfeeding period, immunization, previous diseases and nutritional status as classified by Waterlow and modified by Batista and Z score), to the families (mother's age, total amount of children and of children younger than five years) and to the hygiene habits (handwashing, type of water source). The chi-square test was employed to assess the association between the variables with a $95 \%$ confidence interval $(\mathrm{CI})$ and also to evaluate associations with odds ratio (OR).

\section{Results}

The majority of the 84 children were younger than 24 months: $22(52.3 \%)$ in community 1 and $24(57.1 \%)$ in community 2. Median age was 21.5 months ( \pm 10.1 months) in community 1 and 20.5 months ( \pm 10.6 months) in community 2. The distribution according to sex was similar: $36(42.9 \%)$ girls (community 1: $41.6 \%$ and community $2: 59.1 \%$ ) and 48 (57.1\%) boys (community $1: 58.4 \%$ and community $2: 40.9 \%$ ). There was a preponderance of boys but without significance $(\mathrm{p}<0.05)$.

The every other day follow up visit was successfully completed and no lost occurred.

\section{Incidence, Duration and Prevalence of Diarrhea}

The prevalence of diarrhea found at the moment of the first visit was $3.6 \%$. There was no significant difference on the incidence of diarrhea between the two slums. During the one-year period of observation, a total of 232 episodes of diarrhea were identified, resulting in approximately 2.8 episodes per child per year (2.6 episodes per child per year in community 1 and 2.9 episodes per child per year in community 2), ranging from 1 to 18 episodes per child per year. Twentyone $(25.0 \%)$ children did not present any episode of diarrhea during the whole observation period; 13 (61.9\%) of them lived in community 2 . The average number of children affected per month was $5.0(5.9 \%)$.

The total number of days of diarrhea registered was 936, resulting in an average of 11.1 days of diarrhea per child per year ( 9.8 days of diarrhea per child per year in community 1 and 12.5 days of diarrhea per child per year in community 2). The total duration of diarrhea ranged from 0 to 85 days per child per year. The average duration was 3.9 days per episode per child per year.

Association of the Number of Episodes ( $>3$ ) and the Duration ( $>6$ days) of Diarrhea with Independent Variables

When all 84 children were considered, several differences were observed. However, most of them did not reach statistic significance, as shown in Table 1.

Stature/age ratio inferior to $-1 \mathrm{Z}$ score was an associated factor for suffering a greater number of episodes of diarrhea: children with low stature were almost three times more likely to have more than three episodes per year than their normal counterparts. Sex, age and early weaning were also found to be associated factors for a longer duration of episodes of diarrhea. Male children had their risk of presenting diarrhea for more than six days per year increased more than twice in relation to female children $(\mathrm{p}<0.05)$. Also, infants who were in the first year of life by the beginning of the study were three times more likely to suffer diarrhea than older children $(\mathrm{p}<$ 0.02 ). Weaning on the first month of life was associated with a 2.6 times increased risk for such children to suffer diarrhea for more than six days per year.

Although not all the variables reached statistical significance, some of them showed a tendency toward association. Male sex, previous history of pneumonia, having more than two siblings or a mother who does not wash her hands regularly were possibly associated to the occurrence of three or more episodes of diarrhea per child per year. Other variables, such as the lack of mother's hand washing after children hygiene, were considered to be probably associated with the occurrence of more than six days of diarrhea per child per year. Previous history of pneumonia was associated with increased incidence and duration of diarrhea.

Data were further analyzed for differences between the communities. In community 1 , the occurrence of more than three episodes of diarrhea per child per year was associated with male sex, weight/height ratio inferior to $-1 \mathrm{Z}$ score and previous history of pneumonia. Mothers younger than 25 years old or who had more than three children or who considered her child malnourished were also associated with increased incidence of diarrhea in children from community 1 , but not for those from community 2 . In both communities, age under one year, exclusive breastfeeding period shorter than one month and stature/age ratio inferior to $-1 \mathrm{Z}$ score were found to be associated factors for the occurrence of three or more episodes of diarrhea per child per year (Table 2).

Regarding the duration of the episodes of diarrhea (Table 3 ), it was observed that, in community 1 , chronic malnutrition (indicated by stature/age ratio $<-1$ and weight/height ratio $<$ -1) was associated to an increased risk for children to present episodes of diarrhea lasting more than six days. Furthermore, belonging to a family with more than one child younger than five years old, being considered malnourished by the mother and having a mother who does not wash her hands after children's hygiene were factors associated with longer 
Table 1. Risk factors for increased number of diarrheal episodes and increased number of days with diarrhea during one year

\begin{tabular}{|c|c|c|c|c|}
\hline & \multicolumn{2}{|c|}{ Three or more episodes } & \multicolumn{2}{|c|}{ Six or more days with diarrhea } \\
\hline & $\%$ & Odds ratio (CI 95\%) & $\%$ & Odds ratio (CI 95\%) \\
\hline Male sex & 47.9 & $2.39(0.94-6.17)$ & 58.3 & $2.48(1.01-6.12) *$ \\
\hline Age $<12$ months & 50.0 & $1.78(0.58-5.53)$ & 70.0 & $3.20(0.98-10.84) *$ \\
\hline Exclusive breastfeeding for less than one month & 43.2 & $1.34(0.51-3.57)$ & 62.2 & $2.65(1.00-7.11) *$ \\
\hline Stature/height $<-1.01 \mathrm{Z}$ & 57.7 & $2.89(0.99-8.56) *$ & 65.4 & $2.46(0.84-7.34)$ \\
\hline Previous pneumonia & 54.5 & $2.04(0.49-8.72)$ & 72.7 & $3.23(0.70-16.89)$ \\
\hline Two or more siblings & 46.2 & $2.19(0.85-5.81)$ & 53.8 & $1.71(0.69-4.22)$ \\
\hline Mother's age $<25$ yr & 42.5 & $1.65(0.62-4.40)$ & 54.8 & $1.61(0.62-4.19)$ \\
\hline Mother does not wash hands habitually & 40.5 & $2.72(0.26-67.05)$ & 49.4 & 1 \\
\hline Mother does not wash hands after child hygiene & 40.0 & 1 & 66.7 & $2.29(0.52-11.81)$ \\
\hline
\end{tabular}

$* \mathrm{p}<0.05$.

Table 2. Risk factors for a single child to suffer three or more diarrheal episodes over one year among children living on both slums

\begin{tabular}{|c|c|c|c|c|}
\hline & \multicolumn{2}{|r|}{$\begin{array}{c}\text { Community } 1 \\
\text { Sewerage absent }\end{array}$} & \multicolumn{2}{|r|}{$\begin{array}{c}\text { Community } 2 \\
\text { Sewerage present }\end{array}$} \\
\hline & $\%$ & Odds ratio (CI 95\%) & $\%$ & Odds ratio (CI 95\%) \\
\hline Male sex & 53.8 & $5.06(1.16-25.79)$ & 40.9 & $1.20(0.36-4.68)$ \\
\hline Age $<12$ months & 50.0 & $1.67(0.32-8.71)$ & 50.0 & $1.91(0.37-10.10)$ \\
\hline Exclusive breastfeeding for less than one month & 42.9 & $1.16(0.26-5.15)$ & 43.5 & $1.67(0.39-7.22)$ \\
\hline Height/age $<1.01 \mathrm{Z}$ & 60.5 & $2.73(0.52-15.14)$ & 56.3 & $3.43(0.73-17.08)$ \\
\hline Stature/height $<-1.01 \mathrm{Z}$ & 75.0 & $4.93(0.39-136.5)$ & 16.7 & 1 \\
\hline Previous pneumonia & 66.7 & $3.54(0.45-32.95)$ & 40.0 & 1 \\
\hline Child is considered malnourished by the mother & 66.7 & $3.20(0.20-98.28)$ & 40.0 & $1.11(0.21-5.86)$ \\
\hline Two or more siblings & 48.1 & $2.55(0.64-11.12)$ & 44.0 & $1.89(0.50-7.48)$ \\
\hline Mother's age $<25 \mathrm{yr}$ & 50.0 & $2.00(0.48-8.53)$ & 50.0 & $1.43(0.34-6.19)$ \\
\hline
\end{tabular}

Table 3. Risk factors for a single child to suffer six or more days of diarrhea over one year among children living on both slums

\begin{tabular}{|c|c|c|c|c|}
\hline & \multicolumn{2}{|r|}{$\begin{array}{c}\text { Community } 1 \\
\text { Sewerage absent }\end{array}$} & \multicolumn{2}{|c|}{$\begin{array}{c}\text { Community } 2 \\
\text { Sewerage present }\end{array}$} \\
\hline & $\%$ & Odds ratio (CI 95\%) & $\%$ & Odds ratio (CI 95\%) \\
\hline Male sex & 53.8 & $1.49(0.68-10.12)$ & 63.6 & $2.63(0.73-9.43)$ \\
\hline Age $<12$ months & 60.0 & $2.19(0.42-11.87)$ & 80.0 & $5.14(0.79-41.97)$ \\
\hline Exclusive breastfeeding for less than one month & 57.1 & $2.06(0.47-9.31)$ & 65.2 & $3.21(0.76-14.09)$ \\
\hline Height/age $<1.01 \mathrm{Z}$ & 70.0 & $3.69(0.66-22.86)$ & 62.5 & $1.67(0.37-7.64)$ \\
\hline Stature/height $<-1.01 \mathrm{Z}$ & 75.0 & $2.29(0.18-62.90)$ & 50.0 & 1 \\
\hline Previous pneumonia & 66.7 & $2.80(0.36-25.80)$ & 80.0 & $4.22(0.37-109.4)$ \\
\hline Child is considered malnourished by the mother & 66.7 & $2.59(0.16-79.15)$ & 50.0 & 1 \\
\hline Two or more siblings & 48.1 & $1.39(0.38-5.27)$ & 60.0 & $2.14(0.59-7.78)$ \\
\hline Mother's age $<25 \mathrm{yr}$ & 55.6 & $2.08(0.51-8.78)$ & 54.2 & $1.18(0.29-4.81)$ \\
\hline Mother does not wash hands after child hygiene & 80.0 & $5.87(0.64-151.1)$ & 50.0 & $0.90(0.09-9.42)$ \\
\hline Missed immunizations & 48.1 & $1.39(0.32-6.08)$ & 59.3 & $2.18(0.58-8.26)$ \\
\hline
\end{tabular}

episodes of diarrhea. On the other hand, in community 2, children younger than one year or who had pneumonia were more prone to suffer episodes of diarrhea lasting more than six days. Male sex, exclusive breastfeeding period shorter than one month, inappropriate immunization, having two or more siblings and mother's age inferior to 25 years were associated with longer episodes of diarrhea regardless the sanitary condition of the slum.

\section{Discussion}

Herein is presented the first Brazilian prospective study on diarrhea in which domiciliary visitation was made every 
other day for one year. This method differs from other studies which collected data on home visits once in a month [21,22], fortnightly [15,20], and once [4,8,14], twice [23-25] or three times $[26,27]$ in a week. To our knowledge, the study from Haque et al. [12] is the only one with the same methodology to ours published to date. It has already been noted that more frequent interviews increase the reliability of data collected, as intervals longer than two days may result in falsely decreased estimates of diarrheal episodes, which is possibly due to informants' poor recalling ability $[6,7,28]$.

The average incidence and duration of diarrheal episodes that we found are in accordance with the expectations of the World Health Organization and the Panamerican Health Organization for children who live in poor conditions in developing countries $[29,30]$. We found no significant difference on the incidence of diarrhea between the two slums, while most children who did not have a single episode of diarrhea during the period of observation lived in community 2 , where sewerage is present.

Studies carried out in developing countries reveal the importance of boys' greater environmental exposure for a greater likelihood of suffering diarrhea $[14,20]$. On this study, boys had a higher incidence and, more importantly, a longer duration of the episodes of diarrhea than girls. The importance of environmental exposition to the occurrence of more episodes of diarrhea is demonstrated by the four-time increased risk for boys living in community 1 to suffer more episodes of diarrhea than boys who live in community 2 . It may be attributed to the presence of a better sanitary system that theoretically decreases environmental exposition to pathogens.

There is great agreement that children younger than two years are the most affected by diarrhea $[9,13,15]$ while some have identified an increased incidence of diarrhea in children younger than one year $[1,4,14]$. Our data indicated that both the number of episodes and the duration of diarrhea were greater in that age range. Another point to deserve special attention on that issue is early weaning, which exposes infants to environmental contaminants in poor hygiene conditions. Thus, early weaning is a putative factor to the onset of diarrhea in this age range, chiefly in infants younger than six months $[4,16]$. The protective effect of breastfeeding to infants younger than six months is well established, as well as the role of immunizations. Early weaning and incomplete immunizations have a synergistic effect in enhancing disease.

In our study, stature/age ratio inferior to $-1.01 \mathrm{Z}$ score was an associated factor to increased incidence of diarrhea and was possibly associated to a longer duration of the episodes. Since this nutritional evaluation refers to nutritional status in the beginning of the study, one can assume that this degree of malnutrition favored the occurrence of more episodes of diarrhea during the year of observation. A weight/stature ratio $<-1$ was shown to be associated to increased incidence of diarrhea in community 1 , where children were more exposed to environmental contamination, while both stature/age and weight/stature ratio $<-1$ were associated with an increased duration of the episodes of diarrhea in community 2 .

Some associated factors that affect that age range are already well set, such as early weaning, which exposes infants to environmental contamination especially in poor sanitation conditions, thus being responsible for the onset of diarrhea in this specific population, mostly on infants younger than six months $[4,16]$. Early weaning was shown to be a factor favoring increased incidence and duration of diarrhea $(p<$ 0.03). The early exposure to other foods, generally cow's milk, in diluted and contaminated preparations exposes children to the major associated factors for diarrhea: contamination and malnutrition. Indeed, early weaning was found to be an associated factor for increased incidence of diarrhea and is possibly associated with increased duration.

Other factors also contributed to increase both incidence and duration of diarrhea. Inappropriate immunization favored longer episodes of diarrhea regardless the sanitary conditions. Previous pneumonia was related to increased incidence of diarrhea in community 1 and to increased duration of the episodes in community 2 . Pneumonia is considered an indirect health indicator [19] because it reflects both parental care and child's exposition to associated factors for infectious diseases. Still concerning parental care, children who lived in community 1 and were considered malnourished by their mothers were more likely to suffer more episodes of diarrhea and with increased duration. In community 1 , mothers who did not wash their hands after child's hygiene increased the risk of their children to present longer episodes of diarrhea. These factors are associated to family's low educational level, availability of water and to environmental contamination in a community without basic sanitation structure $[17,30]$.

The strengths of the study were the prospective cohort design and the methodological strategy of each other day visitation. As weaknesses, the unknowledged prevalence or seasonal characteristics of diarrhea in those two communities and the no accomplishment of a multivariate analysis hardened the generalizability of the study findings, however the results of this study agreed with the international medical literature. In conclusion, the average number of diarrhea episodes found in this study is similar to that found by others in children living in poor socioeconomic and sanitation conditions. These results reinforce the importance of some associated factors as chronic malnutrition, low age and early weaning to the onset of diarrhea, emphasizing the multifactorial nature of diarrhea.

\section{References}

1. Snyder J.D., Merson M.H. The magnitude of the global problem of acute diarrheal disease: a review of active surveillance data. Bull World Health Organ 1982;60:605-13.

2. Bern C., Martines J., de Zoysa I., Glass R.I. The magnitude of the global problem of diarrheal disease: a ten-year update. Bull World Health Organ 1992;70:705-14.

3. Kosek M., Bern C., Guerrant R.L. The global burden of diarrheal disease, as estimated from studies published between 1992 and 2000. Bull World Health Organ. 2003;81:197-204. 
4. Guerrant R.L., Kirchhoff V., Shields D.S., et al. Prospective study of diarrhoeal illnesses in northeastern Brazil: patterns of disease, nutritional impact, etiologies and risk factors. J Infect Dis. 1983;148:986-97.

5. Baqui A.H., Black R.E., Yunus M., et al. Methodological issues in diarrheal diseases epidemiology: definition of diarrheal episodes. Int J Epidemiol 1991;20:1057-63.

6. Alam N., Henry F.J., Rahaman M.M. Reporting errors in one-week diarrhoea recall surveys: experience from a prospective study in rural Bangladesh. Int $\mathrm{J}$ Epidemiol 1989; $18: 697-700$.

7. Boerma J.T., Black R.E., Sommerfelt A.E., et al. Accuracy and completeness of mothers' recall of diarrhoea occurrence in preschool children in demographic and health surveys. Int $\mathrm{J}$ Epidemiol 1991;20:1073-80.

8. Muhe L., Byass P., Freij L., et al. A one-year community study of under-fives in rural Ethiopia: patterns of morbidity in public health risk factors. Public Health 1995;109:99-109.

9. Lal S. Surveillance of acute diarrhoeal diseases at village level for effective home management of diarrhoea. Indian J Public Health. 1994;38:65-8.

10. Black R.E., Brown K.H., Becker S., et al. Longitudinal studies of infectious diseases and physical growth of children in rural Bangladesh. II. Incidence of diarrhea and association with known pathogens. Am J Epidemiol 1982;115:315-24.

11. Black R.E., Lopez de Romana G., Brown K.H., et al. Incidence and etiology of infantile diarrhea and major routes of transmission in Huascar, Peru. Am J Epidemiol 1989;129:785-99.

12. Haque R., Mondal D., Kirkpatrick B.D., et al. Epidemiologic and clinical characteristics of acute diarrhea with emphasis on Entamoeba histolytica infections in preschool children in an urban slum of Dhaka, Bangladesh. Am J Trop Med Hyg 2003;69:398-405.

13. Gracey M., Walker-Smith A. Diarrheal disease. Nestle Nutrition Workshop Series 1997;38:1-340.

14. Giugliano L.G., Bernardi M.G., Vasconcelos J.C., et al. Longitudinal study of diarrhoeal disease in a peri-urban community in Manaus (Amazon-Brazil). Ann Trop Med Parasitol 1986;80:443-50.

15. Vázquez M.L., Mosquera M., Cuevas L.E., et al. Incidência e fatores de risco de diarréia e infecções respiratórias agudas em comunidades urbanas de Pernambuco, Brasil. Cad Saude Publica 1999; $15: 163-71$

16. Bravo I.L., Cabiol C., Arcuch S., et al. Breast-feeding, weight gains, diarrhea, and malnutrition in the first year of life. Bull Pan Am Health Organ 1984;18:151-64.
17. Briend A. Is diarrhoea a major cause of malnutrition among the under-fives in developing countries? A review of available evidence. Eur J Clin Nutr 1990;44:611-28.

18. Lima A.A.M., Fang G., Schorling J.B., et al. Persistent diarrhea in Northeast Brazil: etiologies and interactions with malnutrition. Acta Paediatr 1992;381:39-44.

19. Guerrant R.L., Schorling J.B., McAuliffe J.F., de Souza M.A. Diarrhea as a cause and an effect of malnutrition: diarrhea prevents catchup growth and malnutrition increases diarrhea frequency and duration. Am J Trop Med Hyg 1992;47(Suppl): 28-35.

20. Moraes L.R., Cancio J.A., Cairncross S., Huttly S. Impact of drainage and sewerage on diarrhoea in poor urban areas in Salvador, Brazil. Trans R Soc Trop Med Hyg 2003;97:153-8.

21. Mahmud A., Jalil F., Karlberg J., Lindblad B.S. Early child health in Lahore, Pakistan: VII. Diarrhoea. Acta Paediatr Suppl 1993;390:79-85.

22. Benicio M.H.A., Monteiro C.A., Zuñiga H.P.P., Rio E.M.B. Estudo das condições de saúde das crianças no município de São Paulo, SP, (Brasil), 1984-1985. IV - Doença diarreica. Rev Saúde Pública 1987;21(1):23-8.

23. Linhares A.C., Gabbay Y.B., Mascarenhas J.D.P., et al. Immunogenicity, safety and efficacy of tetravalent rhesushuman, reassortant rotavirus vaccine in Belém, Brazil. Bull World Health Organ 1996;74:491-500.

24. Gupta D.N., Sircar B.K., Sengupta P.G., et al. Epidemiological and clinical profiles of acute invasive diarrhoea with special reference to mucoid episodes: a rural community-based longitudinal study. Trans R Soc Trop Med Hyg 1996;90:544-7.

25. Baqui A.H., Black R.E., Sack R.B., et al. Epidemiological and clinical characteristics of acute and persistent diarrhoea in rural Bangladeshi children. Acta Paediatr Suppl 1992;381:15-21.

26. Newman R.D., Sears C.L., Moore S.R., et al. Longitudinal study of Cryptosporidium infection in children in Northeastern Brazil. J Infect Dis 1999;180:167-75.

27. Lima A.A.M., Moore S.R., Barboza Jr. M.S., et al. Persistent diarrhea signals a critical period of increased diarrhea burdens and nutritional shortfalls: a prospective cohort study among children in Northeastern Brazil. J Infect Dis 2000;181:1643-51.

28. Ramakrishnan R., Venkatarao T., Koya P.K., Kamaraj P. Influence of recall period on estimates of diarrhoea morbidity in infants in rural Tamilnadu. Indian J Public Health 1999;43:136-9.

29. Organizacion Mundial de la Salud. La salud en las Americas: Brasil. Vol. II. Washington, 1998.

30. Panamerican Health Organization. Health statistics from Americas (Scientific publication no. 567). Washington, 1998. 